\title{
Controlling the crystallization of porous organic cages: molecular analogs of isoreticular frameworks using shape-specific directing solvents
}

\author{
Tom Hasell, ${ }^{*} \dagger$ Jamie L. Culshaw, ${ }^{\dagger}$ Samantha Y. Chong, ${ }^{\dagger}$ Marc Schmidtmann, ${ }^{\dagger}$ Marc A. Little, ${ }^{\dagger}$ \\ Kim E. Jelfs, ${ }^{\dagger}$ Edward O. Pyzer-Knapp, ${ }^{\S}$ Hilary Shepherd, ${ }^{\dagger}$ Dave J. Adams, ${ }^{\dagger}$ Graeme M. Day ${ }^{\dagger}$ and \\ Andrew I. Cooper ${ }^{*} \dagger$ \\ ${ }^{\dagger}$ Department of Chemistry and Centre for Materials Discovery, University of Liverpool, Crown St., Liverpool L69 \\ 7ZD, UK \\ ${ }^{\ddagger}$ Department of Chemistry, University of Southampton, Highfield, Southampton, SO17 1BJ, UK \\ $\S$ Department of Chemistry, University of Cambridge, Lensfield Road, Cambridge, CB2 1EW, UK
}

KEYWORDS Porous organic cages; covalent organic frameworks; metal-organic frameworks; crystalline; amorphous; microporous; polymorph.

\begin{abstract}
Small structural changes in organic molecules can have a large influence on solid-state crystal packing, and this often thwarts attempts to produce isostructural series of crystalline solids. For metal-organic frameworks and covalent organic frameworks, this has been addressed by using strong, directional intermolecular bonding to create families of isoreticular solids. Here we show that an organic directing solvent, 1,4-dioxane, has a dominant effect on the lattice energy for a series of organic cage molecules. Inclusion of dioxane directs the crystal packing for these cages away from their lowest-energy polymorphs to form isostructural, 3-dimensional diamondoid pore channels. This is a unique function of the size, chemical function, and geometry of 1,4-dioxane, and hence a non-covalent auxiliary interaction assumes the role of directional coordination bonding or covalent bonding in extended crystalline frameworks. For a new cage, $\mathbf{C C}_{13}$, a dual, interpenetrating pore structure is formed which doubles the gas uptake and the surface area in the resulting dioxanedirected crystals.
\end{abstract}

\section{INTRODUCTION}

Synthetic control over pore structure and topology is central to most applications of microporous materials. ${ }^{1}$ This has been achieved in crystalline zeolites ${ }^{2}$ and in other extended networks and frameworks, such as metalorganic frameworks (MOFs),,$^{3-6}$ covalent organic frameworks (COFs), ${ }^{7,8}$ and organic polymer networks. ${ }^{9-11}$ There is also growing interest in porous materials composed of discrete organic ${ }^{12-19}$ or metal-organic ${ }^{20-23}$ molecules. For example, in 2009, we reported a class of cycloimine cage compounds with gas uptakes that are unusually high for molecular organic crystals. ${ }^{24}$ Other porous organic cages were also described recently, both prepared via imine condensation, ${ }^{25-28}$ and by direct carbon-carbon bond formation. ${ }^{29}$ The rapid development of this field since 2009 is demonstrated by the increase in surface areas attained for organic cage molecules, with surfaces areas as high as $2071 \mathrm{~m} \mathrm{~m}^{2} \mathrm{~g}^{-1}$ reported by Mastalerz et al..$^{30}$ The same group also prepared a hydrogen-bonded molecular solid with a remarkable surface area of more than $2800 \mathrm{~m}^{2} \mathrm{~g}^{-1}$.

A distinguishing feature of porous organic molecules ${ }^{15}$ is that they can be dissolved in common solvents, allowing processing options that are unavailable for insoluble frameworks. Solubility allows porous organic cages to be combined in a modular way, creating binary ${ }^{31}$ and also ternary porous co-crystals. ${ }^{32}$ Cage molecules can also be cast into composite membranes ${ }^{33}$ and incorporated in macroporous supports. ${ }^{34}$ Porous organic cages were also shown to act as perfect molecular sieves for certain $C_{9}$ aromatic hydrocarbons, ${ }^{35}$ and as components in sensor devices. ${ }^{36,37}$

The vertex functionality in cage molecules can dictate both the crystal packing and the topology of the resulting pore network. For example, a cyclohexane functionalized imine cage, $\mathrm{CC}_{3}-R$, packs in a window-to-window arrangement to generate a $3-\mathrm{D}$ diamondoid pore network. ${ }^{24,38,39}$ By contrast, the equivalent cyclopentane derivative, $\mathbf{C C}_{4}-R$, packs via window-to-arene interactions, ${ }^{40}$ despite its close structural similarity with $\mathrm{CC}_{3}-R$. This exemplifies the difficulty in creating 'isoreticular' families of porous solids using discrete molecules rather than extended frameworks.

Porous molecular solids can show good physicochemical and hydrolytic stability ${ }^{39}$ and might therefore compete 
with extended frameworks for certain applications. However, the purposeful design of molecular organic solids for specific tasks is challenging, again because small changes in molecular structure can have a pronounced and unpredictable effect on the resulting crystal packing, and hence the solid state properties. Desiraju, pointed out the lack of generality in the underpinning self assembly rules for organic crystals ${ }^{41}$ and the argument was taken further by Schön and Jansen, who suggested that "design" in solid-state chemical synthesis might for this reason be considered "an illusion". ${ }^{42}$ 
a)

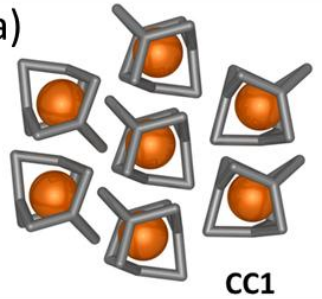

CC1

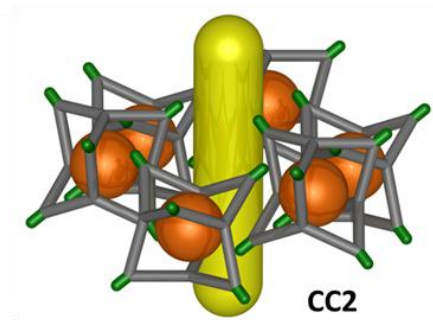

CC2 b)

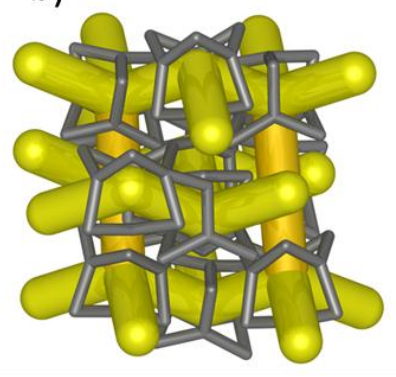

1,4-dioxane

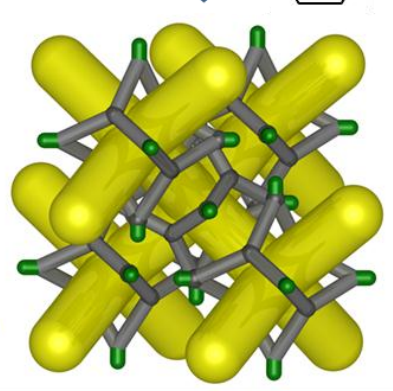

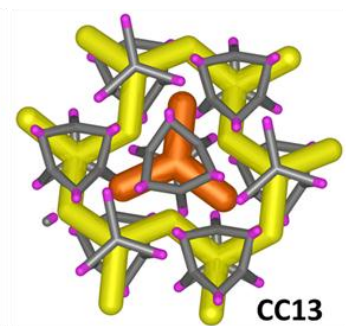

CC13

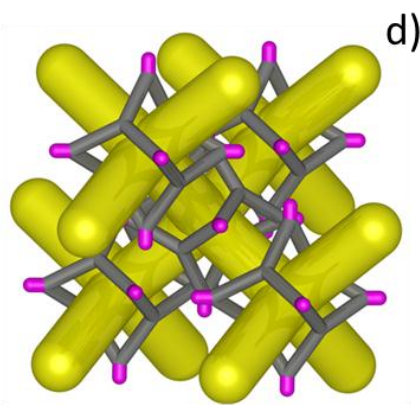

c)

d)
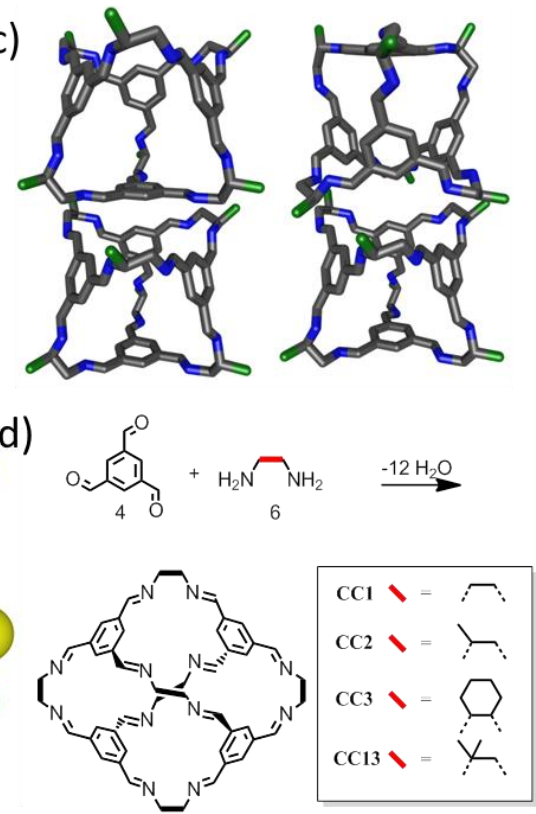

Figure 1. a) Schematic low-energy crystal packings for $\mathbf{C C}_{1}$ (hydrogens on vertices; formally non-porous), $\mathbf{C C}_{2}$ (methyl vertices; 1-D extrinsic pore channels), and $\mathrm{CC}_{13}$ (dimethyl vertices; 2-D layered pore structure with formally disconnected voids). As such, small structural changes to the vertex groups lead to three quite different crystal packings and pore topologies for the $\alpha$ polymorphs shown

here (orange $=$ disconnected voids; yellow $=$ interconnected pores); $\mathrm{b}$ ) Crystallization in the presence of 1,4-dioxane causes pseudoisostructural window-to-window packing for all three cage modules, causing the materials to mimic the 3-dimensional diamondoid pore structure of $\mathbf{C C}_{\mathbf{3}}$ (not shown). This is reminiscent of isoreticular MOFs, where the same pore topology is obtained for a range of different organic linkers; c) The structure of $\mathbf{C C}_{2} \alpha$ comprises window-to-arene packing between the cages (left), while the structure of the 1,4-dioxane-directed polymorph, $\mathbf{C C}_{2} \boldsymbol{\beta}$, comprises window-to-window cage packing (right); d) Synthesis of organic cage modules, $\mathbf{C C}_{\mathbf{1}}, \mathbf{C C}_{\mathbf{2}}, \mathbf{C C}_{3}$, and $\mathbf{C C}_{\mathbf{1 3}}$, via a [4+6] cycloimination reaction, allows a series of isostructural cages to be produced with different vertex functionalities (apart from homochiral $\mathrm{CC}_{3}$ (not shown), these cages all show helical chirality and form racemic crystals - see note $S_{1}$ in SI).

It is certainly true that the lattice energy in molecular crystals is often not dominated by a single, directional intermolecular motif, and that this may thwart design. We are attempting to address this problem by developing crystal structure prediction methods to calculate, de novo, the most stable crystal packing for a given organic cage tecton. However, despite early success within a family of rigid organic imine cages, ${ }^{31}$ the full generalization of this strategy is a challenging, long-term goal that will require significant developments: for example, to reduce the computational expense of structure predictions for large, self-assembled molecules. Given the likely timescale for the de novo computational design of molecular crystals to become more routine, there is a need to develop heuristic rules for controlling the assembly of molecular building blocks in organic crystals.

In this study, we address the question of whether it is possible to decouple the effect of molecular structure on crystal packing by introducing strong non-covalent auxiliaries, or 'directomers', to bias the crystal packing in a family of structures towards a particular tectonic interaction.

There are many reasons why one might modify the structure of an organic cage molecule: for example, to alter its intrinsic pore size, or to change its solubility characteris- tics. However, this is also likely to change the crystal packing of the molecule profoundly. For example, our first three organic imine cages, $\mathbf{C C}_{\mathbf{1}}, \mathbf{C C}_{2}$, and $\mathbf{C C}_{\mathbf{3}}$ differed only in the vertex functionalities, and yet the crystal packing and porosity was quite distinct in each case (o-D non-porous, 1-D linear pores, and 3-D diamondoid pores, respectively). ${ }^{24}$ Hence, each chemical modification results in a new crystal packing and a new pore structure. This is quite different from isoreticular $\mathrm{MOFs}^{43-45}$ and $\mathrm{COFs},{ }^{7,8}$ where families of isostructural porous materials are formed with a range of organic linkers, retaining the same framework topology in each case. For isoreticular frameworks, this is achieved by directional interactions that dominate the crystal lattice energy. This is absent in the systems shown in Figure 1a, where the lattice energy comprises weak van der Waals and electrostatic forces. Hence, we must look to other structure-directing agents, such as additional molecular templates, to induce the same kind of 'isoreticular' packing for the cage molecules illustrated in Fig. 1.

We demonstrate here that three different cages, $\mathbf{C C}_{\mathbf{1}}$, $\mathbf{C C}_{2}$, and a new cage, $\mathbf{C C}_{13}$ (Fig. 1a-d), can all be directed to the same three-dimensional, diamondoid window-towindow packing arrangement (Fig. 1c) that is exhibited by $\mathbf{C C}_{3}$. In the case of $\mathbf{C C}_{13}$, a large increase in porosity is 
achieved by solvent-directed control over crystal packing, rather than by increasing the size of the cage modules themselves, as in other recent reports for organic cages with large pore volumes. ${ }^{30,31,46,47}$

\section{METHODS}

Materials: 1,3,5-Triformylbenzene (TFB) was purchased from Manchester Organics, UK and used as received. 2Methyl-1,2-propanediamine was purchased from TCI Europe and used as received. All other chemicals were purchased from Sigma-Aldrich and used as received.

Synthesis: $\mathrm{CC}_{1}$ and $\mathrm{CC}_{2}$ were synthesized as previously described $^{24,48}$ and recrystallized from a 2:1 mixture of dichloromethane and 1,4-dioxane. $\mathbf{C C}_{2}$ is synthesized from the racemic propane 1,2-diamine. CC13: 2-methyl-1,2propanediamine $(1.529 \mathrm{~g}, 0.0173 \mathrm{~mol})$ was dissolved in dichloromethane $(450 \mathrm{~mL})$ in $2 \mathrm{~L}$ round-bottomed flask cooled in an ice bath. 1,3,5-Triformylbenzene (1.875 g, $0.0116 \mathrm{~mol}$ ) was dissolved in dichloromethane $(575 \mathrm{~mL})$ in a pressure-equalized dropping funnel and added dropwise over 24 hours to the 2-dimethyl-1,2-propanediamine solution with stirring. The reaction mixture was allowed to stir for a further 72 hours at room temperature upon complete addition and the reaction monitored by ${ }^{1} \mathrm{H}$ NMR. The solution was filtered and concentrated down to $\sim 30 \mathrm{~mL}$ using a rotary evaporator at $2 \mathrm{O}^{\circ} \mathrm{C}$. The solids were then isolated by precipitation by addition to excess petroleum ether to give the product as a white powder. The product was vacuum dried overnight to yield $\mathrm{CC}_{13 \alpha}$ as a white powder in $81 \%$ yield $(2.257 \mathrm{~g})$. $\mathrm{CC}_{13} \boldsymbol{\beta}$ was prepared by dissolving $\mathrm{CC}_{13}$ in dichloromethane in a small vial that was placed in a larger vial containing 1,4-dioxane to allow slow diffusion. ${ }^{1} \mathrm{H}$ NMR $\left(\mathrm{CDCl}_{3}, 400 \mathrm{MHz}\right) \delta 8.21$ 8.11 (m, $1 \mathrm{H},-\mathrm{CH}=\mathrm{N}), 8.01-7.88(\mathrm{~m}, 1 \mathrm{H},-\mathrm{ArH}), 3.80(\mathrm{~s}, 1 \mathrm{H}$, $\left.\mathrm{N}-\mathrm{CH}_{2-} \mathrm{C}\right),{ }_{1.51}\left(\mathrm{~s}, 3 \mathrm{H},-\mathrm{C}\left(\mathrm{CH}_{3}\right)_{2}\right) .{ }^{13} \mathrm{C}$ NMR $\left(\mathrm{CDCl}_{3}, 100\right.$ $\mathrm{MHz}) \delta$ 161.2-160.7, 155.5-155.0, 137.1-136.6, 129.3, 72.4, 61.3, $25.9 \mathrm{ppm}$. Acc. Mass MS $\mathrm{m} / \mathrm{z}=961.6$ for $\mathrm{C}_{60} \mathrm{H}_{72} \mathrm{~N}_{12}[\mathrm{M}]^{+}$. CHN Calc. C: $74.97, \mathrm{H}: 7.55, \mathrm{~N}: 17.48$; found C: $74.04, \mathrm{H}$ : 7.35, N: 17.55 .

Single Crystal Data for $\mathrm{CC}_{1}, \mathrm{CC}_{2}, \mathrm{CC}_{13} \alpha$ and $\mathrm{CC}_{13} \beta$. Single crystals were mounted in paratone oil on a MiTeGen mount and flash cooled to $100 \mathrm{~K}$ under a dry nitrogen gas flow. Single crystal X-ray data were measured on a Rigaku MicroMax-o07 HF rotating anode diffractometer (Mo-K $\alpha$ radiation, $\lambda=0.71073 \AA$ )., Kappa 4circle goniometer, Rigaku Saturn724+ detector or for $\mathrm{CC}_{2} \cdot \mathrm{CH}_{2} \mathrm{Cl}_{2} \cdot 3$ (1,4-dioxane) $\cdot \mathrm{H}_{2} \mathrm{O}$ at Beamline I19, Diamond Light Source, using silicon double crystal monochromated radiation $(\lambda=0.6889 \AA)$. An empirical absorption correction using equivalent reflections was performed with the program SADABS; ${ }^{49}$ the structure was solved with the program SHELXD ${ }^{50}$ and refined by a full matrix on $\mathrm{F}^{2}$ by SHELXL ${ }^{50}$ interfaced through the programme OLEX2..$^{51}$ In general all non-H atoms were refined anisotropically, $\mathrm{H}$ atoms were fixed in geometrically estimated positions using the riding model. Friedel pairs were merged in the absence of heavy scatterers.

Crystal data for 2 (CC1) 7 (1,4-dioxane) $\cdot \mathrm{H}_{2} \mathrm{O}$ : Formula $\mathrm{C}_{124} \mathrm{H}_{154} \mathrm{~N}_{24} \mathrm{O}_{15}, M=2220.72 \mathrm{~g} \cdot \mathrm{mol}^{-1}$, monoclinic space group $P_{2_{1}} / c$, colourless crystal, $a=27.968(2), b=18.649$ (1), c = 26.497(2) $\AA, \beta=116.638(2)^{\circ}, V=12353(2) \AA^{3}, Z=4$, $\rho=1.193 \mathrm{~g} \cdot \mathrm{cm}^{-3}, \mu=0.080 \mathrm{~mm}^{-3}, F(\mathrm{ooo})=4737$, crystal size $=0.12 \times 0.04 \times 0.04 \mathrm{~mm}^{3}, T=100(2) \mathrm{K} .181237$ reflec tions measured $\left(1.63<\Theta<23.26^{\circ}\right), 17732$ unique $\left(R_{\text {int }}=\right.$ o.0772), 13008 observed ( $I>2 \sigma(I)), R_{1}=0.0499$ for the observed and $R_{1}=0.0768$ for all reflections, $\mathrm{max} / \mathrm{min}$ residual electron density $=0.715$ and $-0.300 \mathrm{e} \cdot \AA^{-3}$, data / restraints $/$ parameters $=17732 / \mathrm{o} / 1527, \mathrm{GOF}=1.019$.

Crystal data for $\mathbf{C C}_{2} \cdot \mathrm{CH}_{2} \mathrm{Cl}_{2} \cdot 3$ (1,4-dioxane) $\cdot \mathrm{H}_{2} \mathrm{O}$ : Formula $\mathrm{C}_{63} \mathrm{H}_{80} \mathrm{~N}_{12} \mathrm{O}_{5} \mathrm{Cl}_{2}, M=1232.30 \mathrm{~g} \cdot \mathrm{mol}^{-1}$, orthorhombic space group Fddd, colourless crystal, a $=23.321(2), \mathrm{b}=23.577(2)$, $\mathrm{c}=26.891(3) \AA, V=14786(2) \AA^{3}, Z=8, \rho=1.107 \mathrm{~g} \cdot \mathrm{cm}^{-3}, \mu=$ $0.133 \mathrm{~mm}^{-3}, F($ ooo $)=5216$, crystal size $=0.09 \times 0.09 \times 0.06$ $\mathrm{mm}^{3}, T=100(2)$ K. 25700 reflections measured $(2.23<\Theta<$ $\left.20.14^{\circ}\right), 1938$ unique $\left(R_{\text {int }}=0.0493\right), 1086$ observed $(I>$ $2 \sigma(I)), R_{1}=0.1534$ for the observed and $R_{1}=0.1896$ for all reflections, $\mathrm{max} / \mathrm{min}$ residual electron density $=0.317$ and -0.237 e. $\AA^{-3}$, data / restraints / parameters $=1938 / 2 / 194$, $\mathrm{GOF}=1.870$. Diffuse electron density residing in the intrinsic CC2 cavity was masked using a solvent masking routine in OLEX2 $2^{51}$ (see SI).

Crystal data for $\mathbf{C C}_{13} \alpha$ : $\left(\mathbf{C C}_{13}\right) \cdot 3 \cdot 67\left(\mathrm{CH}_{2} \mathrm{Cl}_{2}\right)$ Formula $\mathrm{C}_{63.67} \mathrm{H}_{79.33} \mathrm{~N}_{12} \mathrm{Cl}_{7.33}, \quad M=1269.33 \mathrm{~g} \cdot \mathrm{mol}^{-1}$, trigonal space group $P_{3}$, colourless crystal, $a=24.075(2), c=10.715(1) \AA$, $V=5378.3(9) \AA^{3}, Z=3, \rho=1.176 \mathrm{~g} \cdot \mathrm{cm}^{-3}, \mu=0.334 \mathrm{~mm}^{-3}, F$ $($ ooo $)=2010$, crystal size $=0.32 \times 0.07 \times 0.06 \mathrm{~mm}^{3}, T=$ 100(2) K. 46401 reflections measured $\left(1.69<\Theta<20.81^{\circ}\right)$, 7451 unique $\left(R_{\mathrm{int}}=0.0503\right), 4675$ observed $(I>2 \sigma(I)), R_{1}=$ 0.0598 for the observed and $R_{1}=0.0859$ for all reflections, $\mathrm{max} / \mathrm{min}$ residual electron density $=0.139$ and $-0.113 \mathrm{e} \cdot \AA^{-3}$, data $/$ restraints $/$ parameters $=7451 / 204 / 685$, GOF $=$ 0.946. No chemically reasonable model was found for the diffuse lattice solvent. A solvent masking routine in OLEX2, ${ }^{51}$ was performed during refinement (see SI).

Crystal data for $\mathbf{C C}_{13} \boldsymbol{\beta}$ : $\mathbf{C C}_{13} \cdot 3(1,4$-dioxane): Formula $\mathrm{C}_{72} \mathrm{H}_{96} \mathrm{~N}_{12} \mathrm{O}_{6}, M=1225.61 \mathrm{~g} \cdot \mathrm{mol}^{-1}$, cubic space group $F \mathrm{~d}-3$, colourless crystal, a $=25.850$ (9) $\AA, V=17274(1) \AA^{3}, Z=8, \rho$ $=0.943 \mathrm{~g} \cdot \mathrm{cm}^{-3}, \mu=0.061 \mathrm{~mm}^{-3}, F(\mathrm{ooo})=528 \mathrm{o}$, crystal size $=0.18 \times 0.18 \times 0.10 \mathrm{~mm}^{3}, T=100(2) \mathrm{K} .41367$ reflections measured $\left(2.61<\Theta<20.80^{\circ}\right), 765$ unique $\left(R_{\text {int }}=0.0375\right)$, 618 observed $(I>2 \sigma(I)), R_{1}=0.1263$ for the observed and $R_{1}$ $=0.1363$ for all reflections, $\max / \mathrm{min}$ residual electron density $=0.401$ and $-0.228 \mathrm{e} \cdot \AA^{-3}$, data / restraints / parameters $=765 / 1 / 102$, GOF $=1.935$.

Powder X-ray Diffraction: Laboratory powder X-ray diffraction (PXRD) data were collected in transmission mode on samples held on thin Mylar film in aluminium well plates on a Panalytical X'Pert PRO MPD equipped with an high throughput screening (HTS) XYZ stage, Xray focusing mirror and PIXcel detector, using Ni-filtered $\mathrm{Cu} \mathrm{K} \alpha$ radiation. Data were measured over the range 4$50^{\circ}$ in $\sim 0.013^{\circ}$ steps over 60 minutes. Laboratory PXRD data for $\mathrm{CC}_{13} \beta$ were collected on a Bruker D8 Advance diffractometer with $\mathrm{Ge}$-monochromated $\mathrm{Cu} \mathrm{K} \alpha_{1}$ radiation and a LynxEye PSD using a $1 \mathrm{~mm}$ diameter glass capillary with spinning enabled. High resolution synchrotron PXRD data were collected at the In beamline ${ }^{52}$ at Dia- 
mond Light Source on samples contained in $1 \mathrm{~mm}$ diameter glass capillaries, with spinning enabled. The multi analyser crystal (MAC) detector was used for data collections for $\mathrm{CC}_{2} \boldsymbol{\beta}$ and the Mythen-II position sensitive detector for $\mathbf{C C}_{1}$ samples. Indexing, Le Bail fitting, structure solution and refinement were carried out using TOPAS Academic. ${ }^{53}$

Scanning Electron Microscopy. Imaging of the crystal morphology was achieved using a Hitachi S-48oo cold Field Emission Scanning Electron Microscope. Samples were deposited on adhesive carbon tabs before coating with a $2 \mathrm{~nm}$ layer of gold (Emitech K550X sputter coater). Imaging was at a working distance of $8 \mathrm{~mm}$ and a working voltage of $3 \mathrm{kV}$.

Gas Sorption Analysis. Surface areas were measured by nitrogen sorption at 77.3 K. Powder samples were degassed offline at $100{ }^{\circ} \mathrm{C}$ for $15 \mathrm{~h}$ under dynamic vacuum (10-5 bar) before analysis, followed by degassing on the analysis port under vacuum, also at $100{ }^{\circ} \mathrm{C}$. Isotherms were measured using Micromeritics 2020, or 2420 volumetric adsorption analyzer.

Surface area calculations. Interconnected and unconnected surface areas were calculated using Zeo++, ${ }^{54}$ with a probe radii of 1.42 and $1.82 \AA$ for $\mathrm{H}_{2}$ and $\mathrm{N}_{2}$ respectively. ${ }^{55}$ Defect structures for $\mathbf{C C}_{3}$ were also generated and the surface area recalculated (see ESI, Sections 1.1-2 for more details).

Lattice energy calculations. For each cage, the lattice energies of the known $\alpha$ polymorphs and the associated window-to-window packing arrangement were calculated using lattice energy minimization periodic dispersioncorrected solid-state density functional theory (DFT-D3). Calculations were performed in the program $\mathrm{CP}_{2} \mathrm{~K}^{23}$ with the PBE functional, ${ }^{49}$ TZVP-MOLOPT basis set, ${ }^{56} \mathrm{GTH}$ pseudopotentials, ${ }^{57}$ the Grimme- ${ }_{3}$ dispersion correction $^{58}$ and a planewave cutoff of 280 Ry. The known structures of $\mathbf{C C}_{2}$ and $\mathbf{C C}_{13}$ contain a disordered mixture of the isomers, resulting in disorder of the vertex methyl group positions. Calculations on these systems were simplified by modelling the structures of $\mathbf{C C}_{2}$ and $\mathrm{CC}_{13}$ using just one of the possible positional isomers, but calculating the lattice energies of all configurations of this isomer in each crystal structure (see ESI section 5).

Computational investigation of pore structure. The connectivity of the pore structure for $\mathrm{CC}_{13} \beta$ was investigated by 20 ns NPT Molecular Dynamics (MD) simulations using DL_POLY2.20 ${ }^{59}$ and CSFF, ${ }^{60}$ a force field parameterised previously for porous organic imine cages. A single $\mathrm{H}_{2}$ or $\mathrm{N}_{2}$ molecule was started, in separate simulation runs, in either a cage site or in a formally occluded extrinsic site between the cages. This was done to evaluate the pore connectivity, and to see whether it is possible for a gas molecule to jump from one interpenetrating pore network into the other. For further details, see Section 2.2 in the ESI.

\section{RESULTS AND DISCUSSION}

Synthesis of $\mathrm{CC}_{13}$. This cage-forming reaction was relatively slow, as monitored by ${ }^{1} \mathrm{H} \mathrm{NMR}$, in comparison with the equivalent synthesis of $\mathbf{C C}_{\mathbf{1}}$ where the reaction was complete within 24 hours. ${ }^{48}$ Full disappearance of aldehyde protons and reaction completion was not observed for $\mathrm{CC}_{13}$ until 72 hours after complete reagent addition: that is, the reaction was at least 3 times slower than for CC1. The cage was confirmed as a [4+6] cage by accurate mass spectrometry, with a molecular ion with $\mathrm{m} / \mathrm{z}=961.6$ for $\mathrm{C}_{60} \mathrm{H}_{72} \mathrm{~N}_{12}[\mathrm{M}]^{+}$observed.

Directing the crystal packing: $\mathrm{CC}_{2}$. As shown previously for $\mathbf{C C}_{1},{ }^{61}$ it is possible for porous organic cages to form different crystalline polymorphs depending on the crystallization solvent. The resultant orientation and packing of the cages in these polymorphs has a significant effect on the porosity. In cases where the cages pack in a window-to-arene mode, there can be a complete loss of connectivity between the cage voids, and therefore a total loss of porosity. By contrast, when the cages pack window-to-window, this gives an interconnected diamondoid pore network running throughout the structure. $^{24,38,61}$ Here, we targeted this 3-D diamondoid pore structure, which is 'native' to $\mathbf{C C}_{3}{ }^{24}$ for all three cage-crystal systems, $\mathbf{C C}_{1}, \mathbf{C C}_{2}$, and $\mathbf{C C}_{13}$. Threedimensional porosity might have practical advantages in terms of being less susceptible to pore blocking.

First, we searched for a solvent that would direct $\mathbf{C C}_{2}$ to crystallize in a window-to-window form, like $\mathrm{CC}_{3}$. First CC2 was dissolved in a good solvent (dichloromethane or chloroform) and then an antisolvent was added. Crystals were grown either by vial-in-vial diffusion or by slow evaporation from a layered solution. Of a total of 40 antisolvents tested (Table S1, ESI), 39 antisolvents yielded the original $\mathrm{CC}_{2}$ polymorph, $\mathrm{CC}_{2} \boldsymbol{\alpha}$, which has $1-\mathrm{D}$ extrinsic pore channels (Fig. 1a). ${ }^{24}$ This suggests that $\mathrm{CC}_{2} \alpha$ is indeed the most thermodynamically stable polymorph. Uniquely, when the antisolvent was 1,4-dioxane, CC2 was directed to a different crystal packing, initially as a solvate. This packing arrangement was retained after solvent removal to afford a new crystalline polymorph, $\mathbf{C C}_{2} \beta$ (space group Fddd). Refinement of powder X-ray diffraction data shows that the cages in this new polymorph pack in the targeted window-to-window fashion, and that this gives rise to an interconnected 3-D diamondoid pore structure in $\mathrm{CC}_{2} \boldsymbol{\beta}$ (Fig. 1C). The structure of $\mathrm{CC}_{2} \boldsymbol{\beta}$ is very similar to $\mathrm{CC}_{3}{ }^{24}$ which also packs in a window-towindow structure with diamondoid pores. Therefore, 1,4dioxane must interact in a highly specific way with the cage molecules. One factor that can be important in the formation of solvates or inclusion compounds is the proportion of the void space that is occupied by the solvent. 1,4-Dioxane might therefore be preferred over other solvents because it is just the right size to stabilize the cavity that forms between two cage windows in the window-towindow crystal packing. However, other molecules with closely-related structures and similar molecular volumes (Chart 1 ) were also trialled, but these all yielded the $\mathbf{C C}_{2} \alpha$ polymorph. This included 1,3-dioxane, which has effectively the same molecular volume as its 1,4 isomer. A 
shape-specific intermolecular interaction between 1,4dioxane and $\mathbf{C C}_{2}$ must therefore exist in the $\mathbf{C C}_{2} \beta .1,4^{-}$ dioxane solvate that is not present in the other 39 solvents tested.

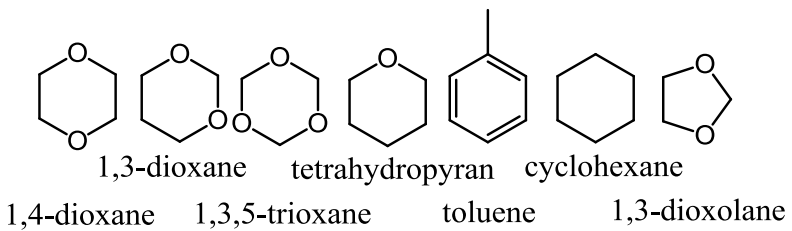

Chart 1: Structure of 1,4-dioxane and some of the structural analogues that were tested as part of the 40 -solvent polymorph screen. Only 1,4-dioxane forms the $\mathbf{C C}_{2} \beta$ polymorph.

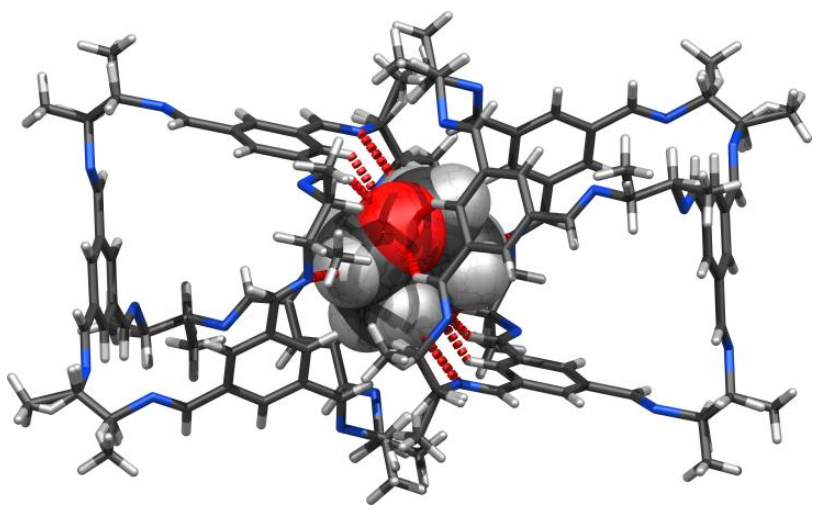

Figure 2. A sum of weak intermolecular interactions is evident between 1,4,-dioxane and the windows of neighboring CC2 $_{2}$ cages in the single crystal solvate structure (see ESI, movie 1 , for a rotating view).

The crystal structure for the $\mathbf{C C}_{2} \boldsymbol{\beta} .1,4$-dioxane solvate shows that a sum of several weak interactions directs $\mathbf{C C}_{2}$ into this crystal packing, rather than a single, specific interaction, (Fig. 2). Effectively, 1,4-dioxane forms a 'peg' between the windows of two adjacent cages, thus directing the cages to a window-to-window configuration and a diamondoid pore structure. This is similar to the $1,4^{-}$ xylene interaction that was reported for linear chains of cage catenanes, ${ }^{62}$ although we note that $p$-xylene does not direct $\mathbf{C C}_{2}$ to crystallize as $\mathbf{C C}_{2} \boldsymbol{\beta}$. Lattice energy calculations, discussed below, suggest that solvent-free $\mathrm{CC}_{2} \boldsymbol{\beta}$ is thermodynamically less stable than $\mathbf{C C}_{2} \alpha$ by about $30 \mathrm{~kJ} \mathrm{~mol}^{-1}$. Hence, specific interactions with 1,4dioxane direct crystallization into this metastable $\boldsymbol{\beta}$ form.

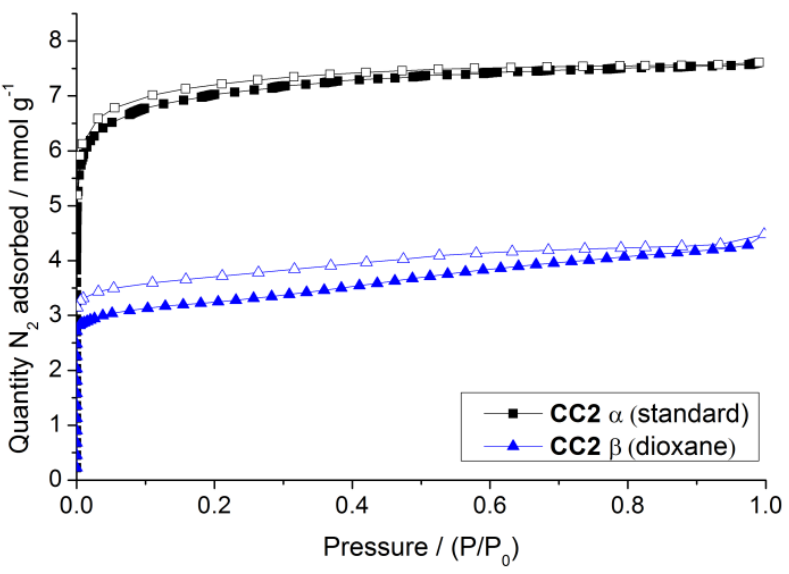

Fig. 3 - Nitrogen sorption isotherms (77 K, 1 bar) for $\mathbf{C C}_{2} \alpha$ and $\mathbf{C C}_{2} \boldsymbol{\beta}$, shown as black squares and blue triangles respectively, adsorption isotherms as closed symbols and desorption isotherms as open symbols.

Both polymorphs show a Type I nitrogen sorption isotherm with a sharp, low-pressure step, indicative of a microporous solid (Fig. 3). Desolvated $\mathbf{C C}_{2} \beta$ is also porous to other gases such as $\mathrm{CH}_{4}, \mathrm{CO}_{2}$, and $\mathrm{H}_{2}$, to a similar level as observed for $\mathrm{C}_{2} \alpha$ (ESI, Figures $\mathrm{S}_{1}-\mathrm{S}_{3}$ ). However, $\mathrm{CC}_{2} \boldsymbol{\beta}$ exhibits a significantly lower uptake of nitrogen than $\mathbf{C}_{2} \alpha$, and a concomitantly lower surface area (330 $\mathrm{m}^{2} \mathrm{~g}^{-1}$ compared to $\left.533 \mathrm{~m}^{2} \mathrm{~g}^{-1}\right)$. $\mathrm{CC}_{2} \boldsymbol{\beta}$ also exhibits a greater slope in the adsorption branch of the isotherm at higher relative pressures, and more pronounced hysteresis in the desorption isotherm. The reduced nitrogen uptake for $\mathbf{C C}_{2} \beta$ can be rationalized from the desolvated crystal structures. $\mathrm{CC}_{2} \alpha$ has both intrinsic porosity (in the cages) and extrinsic porosity (between the cages), which allows nitrogen sorption in both the internal cage cavities and on a proportion of the external cage surface. By contrast, for $\mathbf{C C}_{2} \boldsymbol{\beta}$, only the internal surface of the cages is accessible to nitrogen via the diamondoid channels that run through the cage cavities. In line with this, the crystallographic density for $\mathrm{CC}_{2} \alpha$ is significantly lower than for $\mathbf{C C}_{2} \boldsymbol{\beta}\left(0.876 \mathrm{~g} \mathrm{~cm}^{-3}\right.$ versus $\left.0.915 \mathrm{~g} \mathrm{~cm}^{-3}\right)$. The slope of the $\mathbf{C C}_{2} \boldsymbol{\beta}$ isotherm at higher relative pressure, and the desorption hysteresis, suggests some mesoporous character that cannot be rationalized by the crystal structures. This is explained by pronounced cracking of the $\mathrm{CC}_{2} \boldsymbol{\beta}$ crystals during desolvation (Fig. 4). Cracking of the crystals upon desolvation was not generally observed for our other imine cages and polymorphs, and certainly not to this extent. However, for $\mathbf{C C}_{2} \boldsymbol{\beta}$, this fracturing seems to be unavoidable, even with very slow drying. This is because of the relatively strong directing interaction between the cages and the dioxane molecules, combined with anisotropic changes in the crystal lattice parameters (Table 1 ). Nevertheless, the $\mathbf{C C}_{\mathbf{2}} \boldsymbol{\beta}$ material remains polycrystalline after desolvation $\left(100{ }^{\circ} \mathrm{C}\right.$, dynamic vacuum, 16 hours), and the structure determined from PXRD shows that the window-to-window packing motif and orthorhombic Fddd symmetry is conserved in the desolvated material (Fig. 5). In the solvate, the dimeric cage moiety is slightly expanded to accommodate one dioxane mole- 
cule in the cage cavity and one in the shared window site $\left(d_{\text {cage centroid-centroid }}=10.7(1) \AA\right)$. The position and orientation of the 1,4-dioxane in the window site and dichloromethane molecules in the interstitial site causes a shift of the cage molecules primarily in one direction (Fig. 5), leading to a significantly longer $c$ lattice parameter (Table 1). Upon desolvation, the cages can pack more efficiently $\left(d_{\text {cage centroid-centroid }}=10.1(1) \AA\right)$, with the neighboring windows approaching more closely and the methyl groups moving together in the interstitial sites between cages. This large, anisotropic contraction of the structure upon desolvation, mainly along the $c$ axis, generates mechanical stress within the crystal and results in fracturing.

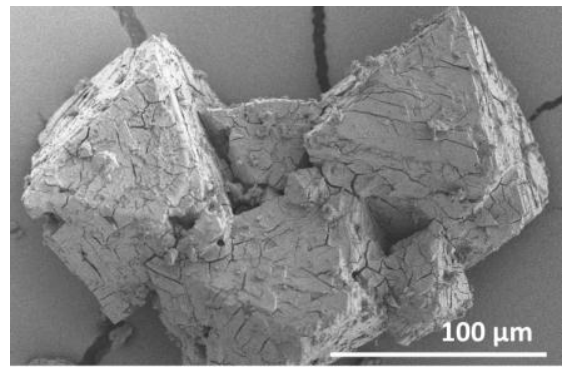

Figure 4. Scanning electron microscopy (SEM) image of octahedral $\mathbf{C C}_{2} \boldsymbol{\beta}$ crystals after desolvation showing significant cracking.
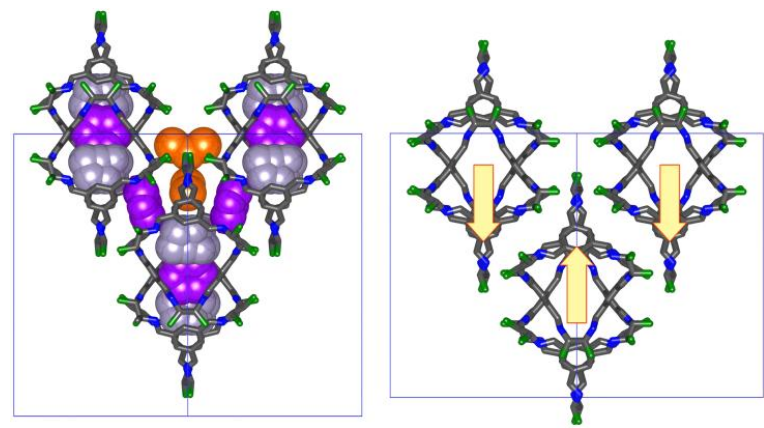

Figure 5. Crystal structure of (left) $\mathbf{C C}_{2}+\left(1,4^{-}\right.$ dioxane) ${ }_{3}+\mathrm{CH}_{2} \mathrm{Cl}_{2}+\mathrm{H}_{2} \mathrm{O}$ and (right) $\mathbf{C C}_{2} \beta$ (desolvated), viewed along [110] direction. The position and orientation of the solvent molecules $\left(\mathrm{CH}_{2} \mathrm{Cl}_{2}\right.$ and 1,4-dioxane shown in orange and purple, respectively) in the $\mathbf{C C}_{\mathbf{2}}$-dioxane solvate expands the packing anisotropically, resulting in a lengthened $c$ axis. Desolvation allows the cage molecules to pack more efficiently in $\mathbf{C C}_{2} \boldsymbol{\beta}$, with a more equivalent set of cell lengths (Table 1).

Table 1. Contraction in the unit cell dimensions of $\mathrm{CC}_{2} \boldsymbol{\beta}$ after desolvation; the contraction is highly anisotropic.

\begin{tabular}{llll}
\hline & CC2+dioxan & CC2 $\beta$ & \% contraction \\
\hline T / K & $100 \mathrm{~K}$ & $293 \mathrm{~K}$ & - \\
a / $\mathrm{A}$ & $23.321(2)$ & $23.2354(6)$ & 0.367 \\
b / & $23.577(2)$ & $23.4819(5)$ & 0.404 \\
c / $\AA$ & $26.891(3)$ & $23.3405(5)$ & 13.203 \\
V / $\AA^{3}$ & $14786(2)$ & $12734.9(5)$ & 14 \\
\hline
\end{tabular}

Compositions:

CC2+dioxane

$\mathrm{C}_{54} \mathrm{H}_{60} \mathrm{~N}_{12^{*}}\left(\mathrm{C}_{4} \mathrm{H}_{8} \mathrm{O}_{2}\right)_{3^{*}} \mathrm{CH}_{2} \mathrm{Cl}_{2^{*}} \mathrm{H}_{2} \mathrm{O}, \mathrm{CC}_{2} \boldsymbol{\beta} \mathrm{C}_{54} \mathrm{H}_{60} \mathrm{~N}_{12}$.

$\mathrm{CC}_{2} \beta$ - Effect of crystallization conditions on microporosity. The precise crystallization conditions that are used to prepare the $\mathrm{CC}_{2} \boldsymbol{\beta}$ material can also substantially affect the porosity. Samples of $\mathrm{CC}_{2} \boldsymbol{\beta}$ showed variable gas uptakes between batches. In principle, the desolvation method might affect the degree of cracking (Fig. 4) and hence the total porosity, but this was ruled out in a parallel synthesis study (Fig. S4), which showed that the method of desolvation had no statistically significant effect on porosity. By contrast, the method used for crystal growth had a major influence, as shown by comparing slow-crystallized samples of $\mathbf{C C}_{2} \boldsymbol{\beta}$ with materials that were precipitated more rapidly from solution by rotary evaporation of solvent (Fig. 6). The apparent BET surface area of the rotary evaporated sample $\left(720 \mathrm{~m}^{2} \mathrm{~g}^{-1}\right)$ was more than twice as high as the slowly crystallized sample $\left(330 \mathrm{~m}^{2} \mathrm{~g}^{-1}\right)$. However, powder diffraction analysis for these two samples suggests, superficially, rather little difference between the two samples, although close inspection does show broader peaks in the PXRD data for the sample produced by rapid crystallization.
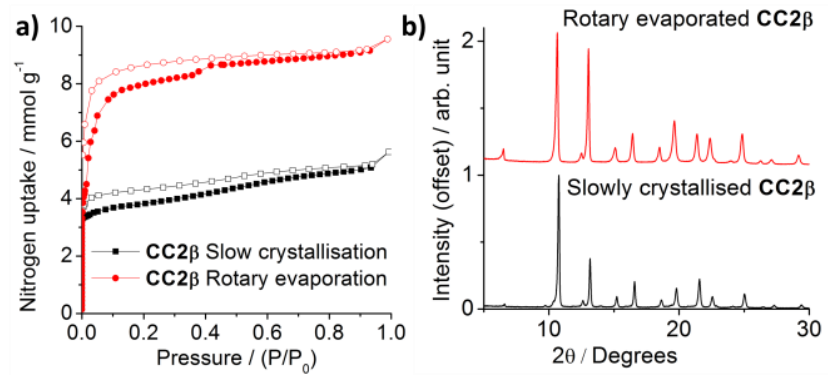

Figure 6. (a) Nitrogen sorption isotherms (77 K) for $\mathbf{C C}_{2} \boldsymbol{\beta}$ crystallized by slow evaporation (black squares) and by rapid rotary evaporation at $30{ }^{\circ} \mathrm{C}$ (red circles). Adsorption isotherms are closed symbols, desorption isotherms are open symbols. (b) Powder XRD patterns of samples of $\mathbf{C C}_{2} \boldsymbol{\beta}$ produced by either slow crystallization or by rotary evaporation.

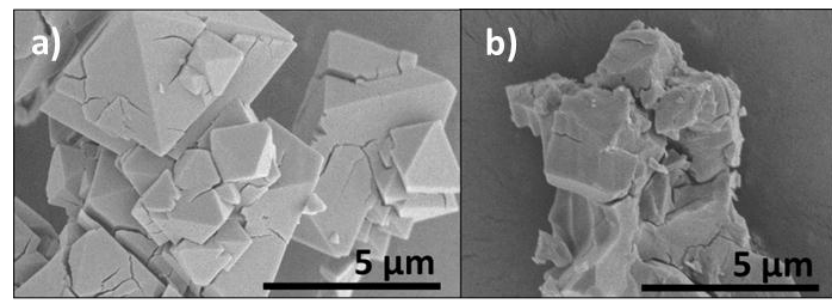

c) Slow, reversible crystal growth:

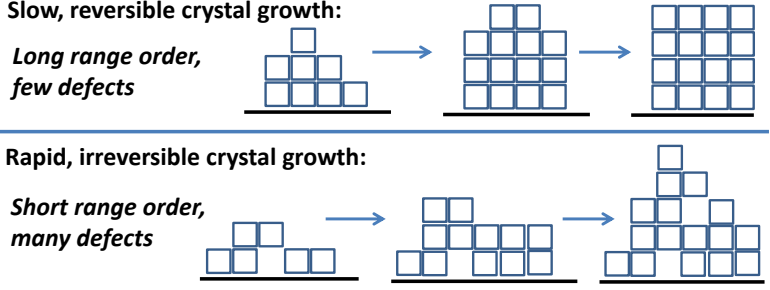

Figure 7. Electron micrographs of samples of $\mathbf{C C}_{2} \boldsymbol{\beta}$ produced by either slow crystallization (a) or by rotary evaporation (b). (c) Schematic representation of crystalline order in these systems. 
This shows that differences in crystallization conditions have a pronounced effect on the resulting nitrogen uptake; much more effect, in this case, than the desolvation method (Fig. S4). We propose that rapidly crystallized $\mathrm{CC}_{2} \beta$ has less extended order and more microporous defects and dislocations, as observed previously for $\mathrm{CC}_{3}{ }^{{ }^{6}}{ }^{3}$ SEM imaging of the two samples shows the slowlycrystallized sample is comprised mainly of regular octahedral crystals, while the rotary evaporated sample has a less regular morphology (Fig. 7). Analysis of the idealized crystal structure for $\mathrm{CC}_{2} \beta$ shows that up to three $\mathrm{N}_{2}$ molecules per cage could be accommodated: one molecule inside the cavity of each cage, and one in each of the four windows shared between two cages. This agrees well with experimental sorption data for the more crystalline samples (ESI, Fig. S5) when only the micropore region is considered (up to $\mathrm{P} / \mathrm{P}_{\mathrm{o}}=0.1 \mathrm{bar}$ ). When rapid crystallization occurs, much higher gas uptakes are observed in the micropore pressure range as a result of defects in the crystals (Fig. 7c). To explore this, a limited computational investigation on the effect of possible local crystal defects, was performed using $\mathbf{C C}_{3}$ as a model (see ESI sections S1.3 and S2.3, Table S2, and Fig. S6). This study showed that an absence of 1 cage in 8 could increase the surface area by $78 \%$. This supports the theory that the higher surface areas observed in rapidly crystallized samples result from a combination of local molecular vacancies in the crystals combined with higher-order defects, such as crystal dislocations and grain boundaries.

Directing the crystal packing: $\mathbf{C C}_{1}$. To test the generality of this solvent-directing approach, similar recrystallizations were performed with the ethanediaminederived cage analogue, $\mathbf{C C}_{\mathbf{1}}$, which lacks the methyl vertex substituents that are present in $\mathbf{C C}_{2}{ }^{24}$ Again, like $\mathbf{C C}_{2}$, none of the polymorphs of $\mathbf{C C}_{1}$ reported until now displays direct window-to-window packing, as found in $\mathrm{CC}_{3}{ }^{61}{ }^{61}$ However, when recrystallized with 1,4-dioxane, CC1 formed a solvate structure with window-to-window packing and strong structural similarities to the CC2.1,4dioxane solvate (Fig. 8). As for CC2, one 1,4-dioxane molecule is located in each window, in addition to another 1,4-dioxane molecule located in the intrinsic cage cavity. However, unlike $\mathbf{C C}_{2}$, only three 1,4-dioxane solvate molecules are shared in an equivalent manner between neighbouring cage windows. The fourth cage window is occupied by a 1,4-dioxane molecule that is not shared between adjacent cage windows, but which is instead located in an extrinsic channel. The packing motif is nonetheless strongly related to the CC2 dioxane solvate, and the window-dioxane tecton interaction is again dominant. (a)
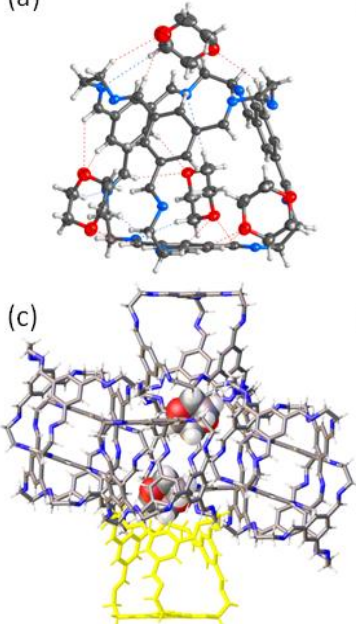

(b)

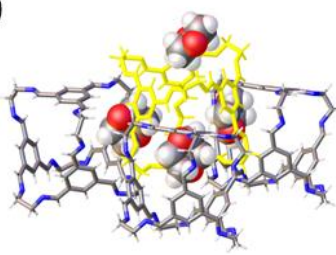

(d)

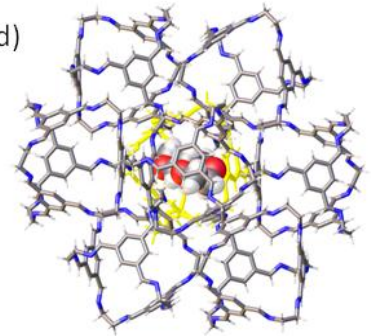

Figure 8. Single crystal X-ray structure for $\left(\mathrm{CC}_{1}\right)_{2} \cdot(1,4-$ dioxane $)_{7}$. a) Displacement ellipsoid plot, ellipsoids displayed at 50\% probability level; 1,4_dioxane molecule located in the intrinsic cavity has been omitted for clarity. Close contacts are evident between 1,4-dioxane molecules positioned in each of the four cage windows and $\mathbf{C C}_{\mathbf{1}}$, as shown by dashed lines. (b) Crystal packing extending from one $\mathrm{CC}_{\mathbf{1}}$ molecule (highlighted in yellow) showing its close window-to-window packing with three neighboring $\mathbf{C C}_{1}$ molecules, and the shared 1,4-dioxane molecules, shown in space-filling format. The fourth window-positioned 1,4-dioxane molecule resides in a 1-D channel generated by the extended lattice. These channels are surrounded by the aromatic face / ethyl vertex of six $\mathbf{C C}_{1}$ molecules, viewed from (c) side, (d) above.

Crystals of the CC1.1,4-dioxane solvate undergo a larger structural change upon desolvation than the $\mathbf{C C}_{2}$.dioxane solvate. Unlike $\mathbf{C C}_{2} \boldsymbol{\beta}$, the $\mathbf{C C}_{1.1,4}$-dioxane solvate is not desolvated to form an equivalently stable, diamondoid porous solid. Rather, when the 1,4-dioxane is removed, the $\mathbf{C C}_{\mathbf{1}}$ cages relax into a mixture of lower-energy, as yet unidentified phases. It is likely that these are structural intermediates lying somewhere between the 1,4-dioxanedirected window-to-window packing, and a lower-energy polymorph of $\mathbf{C C}_{1}$ (see ESI section $\mathrm{S}_{3}$, Fig. S6, $\mathrm{S}_{7}$ ). We rationalize this difference on the basis of the two 1,4-dioxane-containing crystal structures, and the vertex functionalities in $\mathbf{C C}_{1}$ and $\mathbf{C C}_{2}$. In both cases, the window-to-window packing mode is metastable with respect to alternative desolvated polymorphs in the absence of the 1,4-dioxane 'directomer'. Persistence ofthis metastable phase depends on the activationbarrier to cage rearrangement relative to the thermal energy. We believe that the additional methyl functionalization in $\mathbf{C C}_{2}$ explains the persistence of the window-to-window packing after desolvation because these methyl groups inhibit rotation of the cages in $\mathrm{CC}_{2} \boldsymbol{\beta}$ in the solid-state. It is also possible that the greater molecular flexibility of the $\mathbf{C C}_{\mathbf{1}}$ cage, which can interconvert its conformers and its helical chirality in the solid state, ${ }^{62}$ allows conversion to other, lower-energy polymorphs. Coupled with a larger calculated lattice energy gap with respect to the CC1 $\alpha$ polymorph (see below), this explains the lower stability of the CC1.1,4-dioxane structure toward desolvation. 


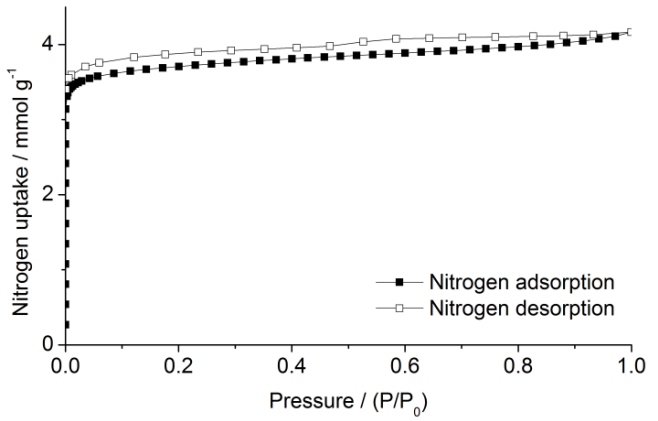

Figure 9. - Nitrogen sorption isotherm (at $77 \mathrm{~K}$ and 1 bar) of a desolvated sample of CC1.1,4-dioxane.

Nitrogen sorption isotherms for desolvated samples derived from the CC1.1,4-dioxane solvate show significant microporosity (Fig. 9), whereas previous polymorphs $\mathrm{CC}_{1} \alpha^{24}$ and $\mathrm{CC}_{1} \beta^{61}$ are non-porous to $\mathrm{N}_{2}$. The apparent BET surface area of $333 \mathrm{~m}^{2} \mathrm{~g}^{-1}$ is comparable with $\mathrm{CC}_{2} \beta$. Hence, despite changes in the crystal packing upon desolvation, a connected pore structure is maintained. This would be expected from the solvent-accessible surface for an in silico desolvated structure (Fig. 10); that is, not allowing for any structural rearrangements. Again, the number of nitrogen molecules adsorbed per cage at $\mathrm{P} / \mathrm{P}_{\mathrm{o}}=0.1$ is 2.7, in fair agreement with the three $\mathrm{N}_{2}$ molecules per cage that would correspond to an idealized and fully occupied structure. The desolvated $\mathbf{C C}_{1}$ material is also porous to hydrogen (ESI, Fig. S8).

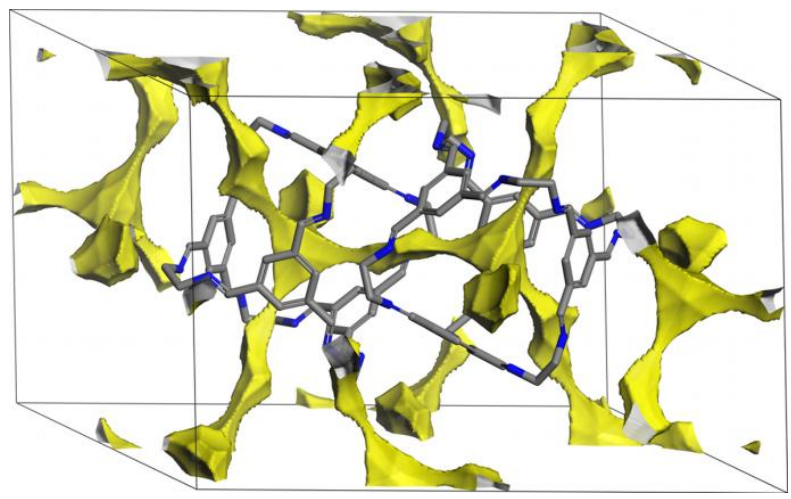

Figure 10. Solvent accessible surface colored yellow for a probe radius of $1.82 \AA$ for $\mathrm{N}_{2}$, for the artificially 'in silico' desolvated crystal structure of CC1.1,4-dioxane, not allowing for any structural rearrangements.

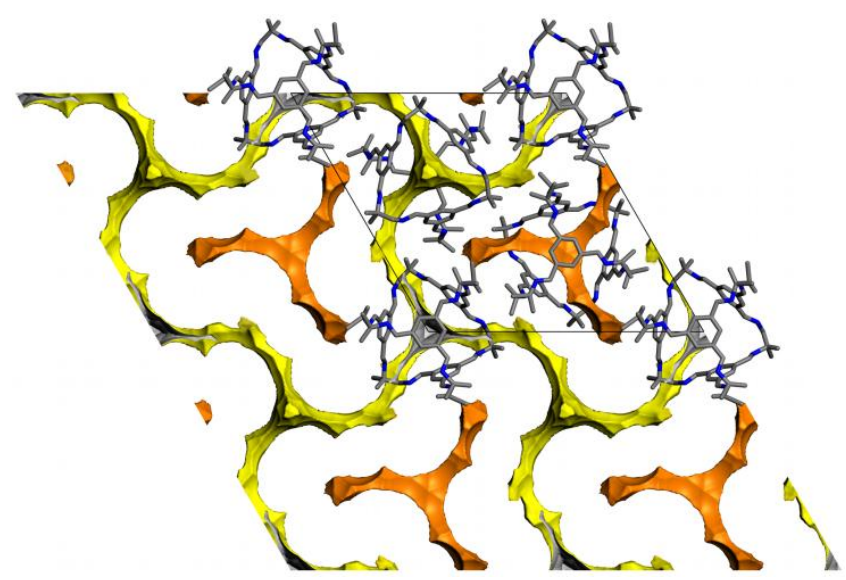

Figure 11. A unit cell of $\mathrm{CC}_{13} \alpha$ viewed down the $c$ axis, shown with the solvent accessible surface for a $\mathrm{N}_{2}$ probe of radius $1.82 \AA$, extended over a $2 \times 2 \times 2$ supercell. Voids which are connected across the cell are shown in yellow, and formally disconnected voids in orange. Hydrogens are omitted.

Directing the crystal packing: $\mathrm{CC}_{13}$. This new cage, synthesized for the first time here, has two germinal methyl substituents per cage vertex whereas $\mathbf{C C}_{2}$ has just one (Fig. 1). Recrystallization of $\mathrm{CC}_{13}$ by layering in dichloromethane and acetone formed crystals in the trigonal space group $P_{3}$. Removal of the solvent caused little disruption to the solvate crystal packing and yielded a crystalline polymorph, $\mathbf{C C}_{13} \boldsymbol{\alpha}$, which packs in a staggered arrangement with no direct window-to-window connections (Fig. 11). The asymmetric unit comprises three $\mathbf{C C}_{13}$ fragments from three crystallographically independent cages. Each cage has threefold rotational symmetry, and the methyl groups are disordered, with 50\% occupancy over the two possible vertex sites. A surface area for the desolvated structure was calculated using an $\mathrm{N}_{2}$ probe radius, and this showed 2-D propeller-shaped cavities that are formally occluded (orange, Fig. 11), in addition to an interconnected 2-dimensional pore network (yellow).The nitrogen sorption isotherm for $\mathrm{CC}_{13} \alpha$ shows significant gas uptake and microporosity (Fig. 12), but with a stepped, Type IV isotherm, similar to that previously observed for another related imine cage, $\mathbf{C C}_{4}-R^{40}$ The cause of these steps is not yet fully understood, but we believe they are due to a subtle phase transition at low pressure, which will be addressed in future work. The apparent BET surface area was $517 \mathrm{~m}^{2} \mathrm{~g}^{-1}$, and the gas uptake was $9.2 \mathrm{mmol} \mathrm{g}^{-1}$ at $\mathrm{P} / \mathrm{P}_{\mathrm{o}}=0.99$, but only $1.1 \mathrm{mmol} \mathrm{g}^{-1}$ in the micropore range at $\mathrm{P} / \mathrm{P}_{\mathrm{o}}=0.1$. The crystal habit of $\mathrm{CC}_{13 \alpha} \mathbf{a}$ is hexagonal needles (Fig. 13a). Again, 1,4-dioxane was evaluated as a 'directomer' for 3-D window-towindow packing. As for $\mathbf{C C}_{1}$ and $\mathbf{C C}_{2}$, the dioxanedirected crystallization induced window-to-window packing in the $\mathbf{C C}_{13}$ solvate. Powder X-ray diffraction showed little structural change upon removal of 1,4-dioxane (Fig. S9-11), yielding a desolvated polymorph, $\mathrm{CC}_{13} \beta$ (Fig. 14a). 


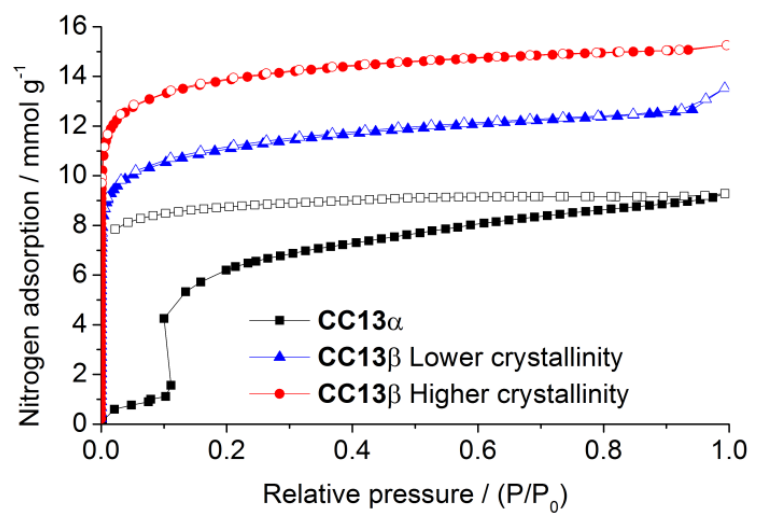

Figure 12. Nitrogen isotherms (at $77 \mathrm{~K}$ and 1 bar) for $\mathbf{C C}_{13} \alpha$ and $\mathrm{CC}_{13} \beta$ (lower and higher crystallinity) polymorphs, apparent BET surface area $=517,946$, and $1173 \mathrm{~m}^{2} \mathrm{~g}^{-1}$ respectively.

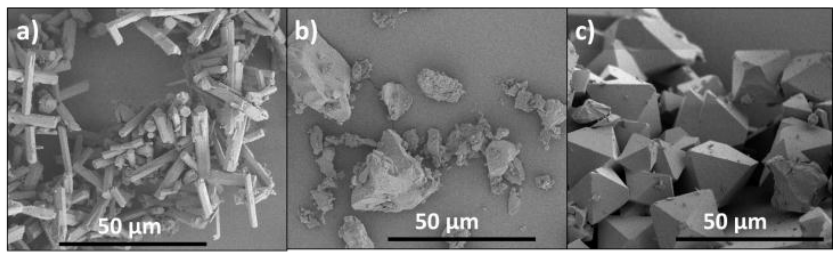

Figure 13. SEM images of samples of $\mathrm{CC}_{13} \alpha$ (a), $\mathrm{CC}_{13} \beta$ of lower crystallinity (b), and $\mathrm{CC}_{13} \boldsymbol{\beta}$ of higher crystallinity (c).

As for $\mathbf{C C}_{13} \alpha$, the geminal methyl groups are disordered and refine with $50 \%$ occupancy in the two possible vertex sites. One molecule of 1,4-dioxane sits inside each cage, with another four molecules of 1,4-dioxane positioned in each cage window, just as for the CC $_{2} \beta .1,4$-dioxane solvate. A Type I isotherm with no steps was observed for desolvated $\mathrm{CC}_{13} \boldsymbol{\beta}$ structure, along with a much higher gas uptake at low relative pressures (Fig. 12). In our first preparation of $\mathrm{CC}_{13} \beta, \mathrm{CC}_{13}$ was dissolved in dichloromethane, 1,4-dioxane was added, and then the solvents were removed by simple evaporation from an open vessel in a fumehood. This gave an apparent BET surface area of $946 \mathrm{~m}^{2} \mathrm{~g}^{-1}$ : almost double that of the $\mathrm{CC}_{13} \alpha$ polymorph. The $\mathrm{N}_{2}$ uptake was $13.5 \mathrm{mmol} \mathrm{g}^{-1}$ at $\mathrm{P} / \mathrm{P}_{\mathrm{o}}=0.99\left(10.5 \mathrm{mmol} \mathrm{g}^{-1}\right.$ at $\mathrm{P} / \mathrm{P}_{\mathrm{o}}=0.1$; Fig. 12, blue points). The low-pressure uptake corresponds to $10.1 \mathrm{~N}_{2}$ molecules per cage: a dramatic increase over the $\sim 3 \mathrm{~N}_{2}$ per cage for $\mathbf{C C}_{1}$ and $\mathbf{C C}_{2}$ in the same packing arrangement. A concern, therefore, was that this stemmed from crystal defects, as discussed above for $\mathbf{C}_{2} \boldsymbol{\beta}$. Therefore, further crystallizations of $\mathbf{C C}_{13}$ were performed using slow, carefully controlled solvent evaporation under a nitrogen flow.

This more careful crystallization procedure gave much more uniform, octahedral crystals (Fig. 13b,c). However, these more regular crystals showed a higher level of microporosity (Fig. 12, red points). Hence, crystal defects cannot be responsible here for the extra porosity in $\mathbf{C C}_{13} \boldsymbol{\beta}$. The highly crystalline sample had an apparent BET surface area of $1173 \mathrm{~m}^{2} \mathrm{~g}^{-1}$, with an $\mathrm{N}_{2}$ uptake of $15.3 \mathrm{mmol} \mathrm{g}^{-1}$ at $\mathrm{P} / \mathrm{P}_{\mathrm{o}}=0.99\left(11.6 \mathrm{mmol} \mathrm{g}^{-1}\right.$ at $\left.\mathrm{P} / \mathrm{P}_{\mathrm{o}}=0.1\right)$, corresponding to $11.1 \mathrm{~N}_{2}$ per cage molecule. By compari- son, high-crystallinity $\mathbf{C C}_{3}$, which packs isostructurally, has a BET surface area of $\sim 400 \mathrm{~m}^{2} \mathrm{~g}^{-1} \cdot{ }^{63} 11 \mathrm{~N}_{2}$ molecules per cage cannot be rationalized based on a single diamondoid pore channel, as observed for $\mathbf{C C}_{2} \beta$ and $\mathbf{C C}_{3}$.

The increased porosity results from the steric bulk of the two geminal methyl groups in $\mathbf{C C}_{13}$ which, like the cyclohexane vertices in $\mathbf{C C}_{3}$, force the cages further apart in the solid-state structure. However, unlike $\mathbf{C C}_{3}$, where the cyclohexane groups fill any extrinsic pore volume, the methyl groups in $\mathbf{C C}_{13} \boldsymbol{\beta}$ do not fill the interstitial sites, and this creates additional, accessible pore volume (Table 2, Fig. 15). The crystalline density of $\mathrm{CC}_{13} \beta$ is hence substantially lower than $\mathrm{CC}_{3}: 0.828 \mathrm{~g} / \mathrm{cm}^{3}$ versus $0.973 \mathrm{~g} \mathrm{~cm}^{-}$ 3 .

On first inspection, these additional extrinsic void volumes are not interconnected, either to each other or to the main intrinsic void network for an $\mathrm{N}_{2}$ gas probe radius (Figs. 14b, S12-13). However, decreasing the probe radius to $1.53 \AA$ just connects the extrinsic sites in the static structure (Fig. S13b, Movie 3). We next investigated the dynamic pore network in $\mathrm{CC}_{13} \boldsymbol{\beta}$ using MD simulations to see whether molecular flexibility allows these pore structures to become interconnected.First, we observed that a single $\mathrm{N}_{2}$ molecule placed inside a cage void diffused throughout the diamondoid, intrinsic pore network (shown in yellow, Fig. 14), visiting all cages in the simulation cell over a 20 ns simulation. At no point did the $\mathrm{N}_{2}$ 'hop' into any of the occluded voids (shown in cyan). We then placed a $\mathrm{N}_{2}$ molecule in one of the formally occluded extrinsic voids and ran a further 20 ns simulation, over which time we observed a single hop between two occluded, extrinsic voids. This suggests mobility of $\mathrm{N}_{2}$ within the cyan-colored extrinsic pore network (Fig. 14b), commensurate with the large increase in $\mathrm{N}_{2}$ uptake (Fig. 12), but at a much slower diffusion rate than in the yellow, intrinsic pore network. To observe more hopping events, we repeated the simulations with a smaller molecule, $\mathrm{H}_{2}$, whereupon all of the extrinsic voids were accessed, forming a secondary, interconnected diamondoid network (Fig. 14c and Movie 4) that is interpenetrated with the primary, intrinsic network. Hence small gases are able to diffuse between the extrinsic, formally occluded voids (Fig. S14) as a result of the flexibility of the cage molecules, which allows transient diffusion pathways.

Table 2 - Comparison of unit cell dimensions for $\mathrm{CC}_{2} \beta$ and $\mathrm{CC}_{13} \beta$.

\begin{tabular}{|l|l|l|l|}
\hline & $\begin{array}{l}\text { Unit cell } \\
\text { length }(\AA)\end{array}$ & $\begin{array}{l}\text { Unit cell } \\
\text { volume }\left(\AA^{3}\right)\end{array}$ & $\begin{array}{l}\text { Accessible vol- } \\
\text { ume (\% and } \\
\left.\AA^{3}\right)^{\ddagger}\end{array}$ \\
\hline $\mathrm{CC}_{2} \boldsymbol{\beta}$ & $\begin{array}{l}23.2354(6), \\
23.4819(5), \\
23.3405(5)\end{array}$ & $12734.9(5)$ & $1.6 \%, 203 \AA^{3}$ \\
\hline $\mathrm{CC}_{13} \boldsymbol{\beta}$ & $24.896(1)$ & $15430(2)$ & $5.4 \%, 828 \AA^{3}$ \\
\hline
\end{tabular}

₹ Based on desolvated structures, with the disorder of the methyl groups randomly assigned, and a $\mathrm{H}_{2}$ probe radius of $1.42 \AA$. 

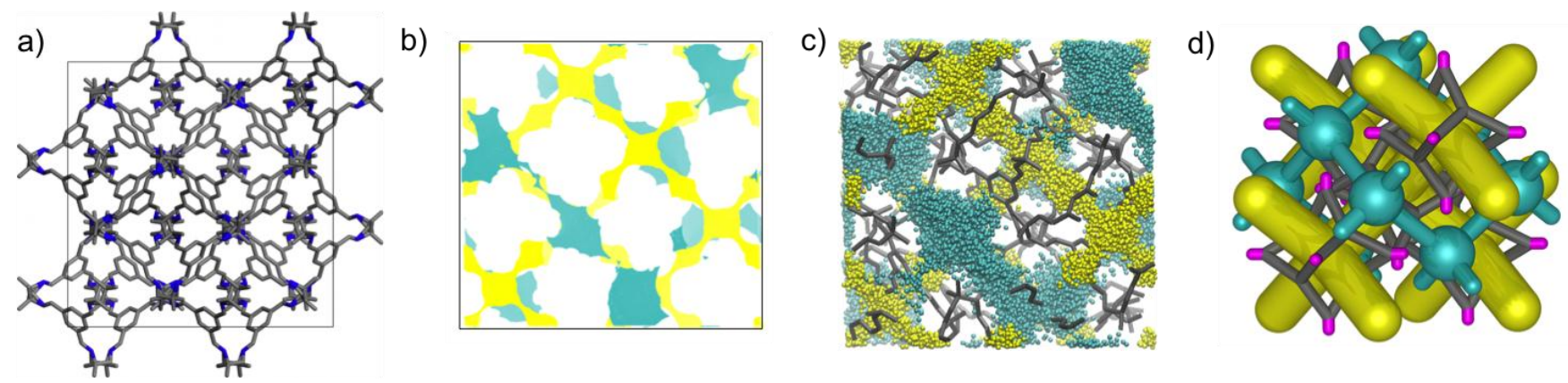

Figure 14. The double, interpenetrating diamondoid pore structure of $\mathbf{C C}_{13} \boldsymbol{\beta}$. (a) The Fd-3 unit cell, with hydrogen atoms omitted; (b) the accessible surface area for a $\mathrm{N}_{2}$ probe of radius $1.82 \AA$, interconnected surface area (ISA) colored yellow, formally unconnected voids colored cyan; (c) an overlay of all the $\mathrm{H}_{2}$ gas positions (sampled every $3.5 \mathrm{ps)} \mathrm{for} \mathrm{a} 20$ ns NPT MD simulation at $300 \mathrm{~K}$ with a single $\mathrm{H}_{2}$ molecule starting in the diamondoid intrinsic void (colored yellow), and a separate MD simulation with $\mathrm{a} \mathrm{H}_{2}$ molecule starting in an occluded site (colored cyan); (d) A scheme of the crystal packing, with two separate, interpenetrated pore networks running through the cages (colored yellow) and the interconnected extrinsic voids (colored cyan).
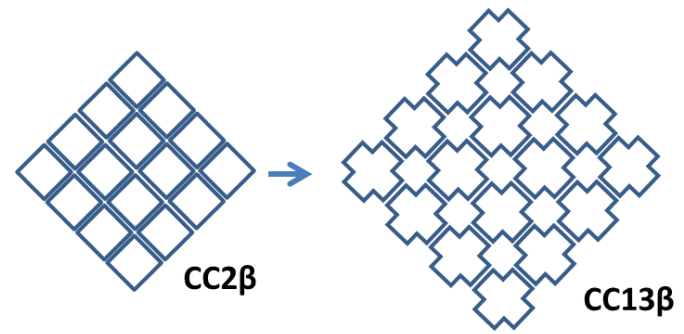

Figure 15. Schematic, 2-dimensional representation of the frustrated packing for $\mathbf{C C}_{\mathbf{1}} \boldsymbol{\beta}$ (two methyl groups per vertex) with respect to $\mathbf{C C}_{2} \boldsymbol{\beta}$ (one methyl group per vertex).

At no point in the MD simulations did we observe any evidence for $\mathrm{H}_{2}$ or other gases hopping between the intrinsic and extrinsic pores networks. Hence, we surmise that $\mathrm{CC}_{13} \boldsymbol{\beta}$ has two separate interpenetrated networks that are isolated from each other, even for the smallest guests, as shown schematically in Fig. 15d. The two interpenetrated pore networks are related crystallographically by translation of the pore nodes by $(1 / 2,1 / 2,1 / 2)$. This double, interpenetrating pore network rationalizes the doubling of the gas uptake in $\mathrm{CC}_{13} \boldsymbol{\beta}$ with respect to its superficially similar diamondoid analogues. As a consequence, $\mathbf{C C}_{13} \beta$ exhibits a significantly higher micropore volume at $\sim 10 \AA$ pore width than the CC1.1,4-dioxane material after desolvation or the analogous $\mathbf{C}_{2} \beta$ phase (Fig. $\mathrm{S} 15)$. The hydrogen uptake for $\mathbf{C C}_{13} \boldsymbol{\beta}$ is $2.0 \mathrm{wt} \%$ at $77 \mathrm{~K}$ and 1 bar (Fig. S16); the highest value reported to date for a porous organic cage, and comparable to many MOFs and the extrinsically porous molecular crystal recently reported by Mastalerz and Oppel. ${ }^{18}$

Interpenetration of pore channels represents a different strategy for increasing guest uptakes, and all other porous organic cages with surface areas of more than 1000 $\mathrm{m}^{2} / \mathrm{g}$ have relied on increasing the size of the cage units themselves. ${ }^{30,31}$ However, increasing the cage size can result in a concomitant decrease in solubility (e.g., for $\left.\mathrm{CC}_{5}\right){ }^{31}$ thereby limiting processability. By contrast, the disordered, geminal methyl groups in $\mathrm{C}_{13}$ strongly increase the solubility with respect to its close structural analogues. Indeed, $\mathbf{C C}_{13}$ is highly soluble in chlorinated solvents, and it has a much higher solubility (c.f., $\mathbf{C C}_{\mathbf{1}}$, $\mathbf{C C}_{2}$ and $\mathbf{C C}_{3}$ ) in non-halogenated solvents such as methanol and tetrahydrofuran. The solubility of $\mathbf{C C}_{13}$ was measured by ${ }^{1} \mathrm{H}$ NMR by comparison to an internal standard, and was found to be around 20 times higher in chloroform than $\mathbf{C C}_{3}$ (200 $\mathrm{mg} / \mathrm{mL}$ c.f., $9 \mathrm{mg} / \mathrm{mL}$ for $\left.\mathbf{C C}_{3}\right)$. Likewise, the solubility of $\mathrm{CC}_{13}$ in methanol and in tetrahydrofuran was $5 \mathrm{mg} / \mathrm{mL}$ and $17 \mathrm{mg} / \mathrm{mL}$, respectively (Table $\mathrm{S}_{3}$ ), while $\mathbf{C C}_{3}$ is barely soluble at all in those solvents.

Calculated lattice energies. To understand the importance of the structure-directing influence of 1,4dioxane, lattice energy calculations were performed on the $\alpha$ forms of cages $\mathbf{C C}_{1}, \mathbf{C C}_{2}$, and $\mathbf{C C}_{13}$ and on the associated window-to-window polymorphs. The aim was to determine the relative stability of the window-to-window packing arrangement compared to the polymorphs that are formed in the absence of the 1,4-dioxane solventtemplating effect. For each of $\mathbf{C C}_{1}, \mathbf{C C}_{2}$ and $\mathbf{C C}_{13}$, calculations confirm that the isostructural window-to-window packing mode is metastable with respect to the relevant $\alpha$ polymorph (Fig. 16). By contrast, no solvent 'directomer' is required to produce window-to-window packing in $\mathbf{C C}_{3}$, which is found as the clear global minimum on the computed lattice energy surface. ${ }^{31}$ The relative energy of the window-to-window packing compared to the $\alpha$ structure is similar for both $\mathrm{CC}_{2}$ and $\mathrm{CC}_{\mathbf{1 3}}$.

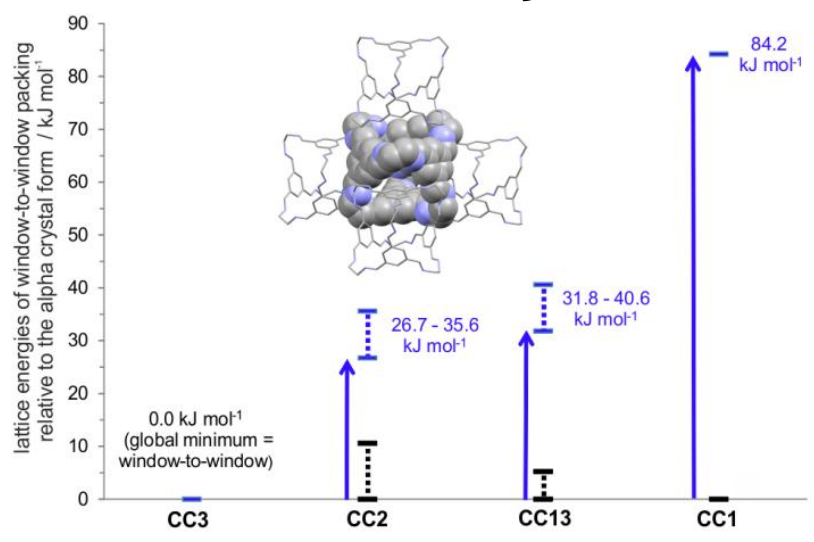


Figure 16. The energetic cost of window-to-window packing relative to the alpha polymorphs for $\mathbf{C C}_{3}, \mathbf{C C}_{2}, \mathbf{C C}_{13}$ and CC1. The energies indicated in blue refer to the window-towindow packing mode for each molecule, relative to the alpha form, calculated using dispersion-corrected DFT. The energy ranges shown for $\mathbf{C C}_{2}$ and $\mathbf{C}_{13}$ refer to the spread in calculated energies that result from the different possible configurations of the vertex methyl groups. The energy ranges shown in black show the corresponding spread in calculated energies for the $\alpha$ form associated with the different vertex methyl group positions.

For both $\mathbf{C C}_{2}$ and $\mathbf{C C}_{13}$, the disorder in the vertex methyl groups leads to variations of up to $10 \mathrm{~kJ} \mathrm{~mol}^{-1}$ in the calculated lattice energy. This spread in energies is similar in both the $\alpha$ form and in the window-to-window structures: hence, any configurational entropy contribution to the relative stability is expected to be small. For both molecules, the calculations highlight the vital role of the 1,4-dioxane 'directomer' in stabilizing the window-towindow packing, which is approximately $30 \mathrm{~kJ} \mathrm{~mol}^{-1}$ less stable than the $\alpha$ form. By comparison with cages $\mathrm{CC}_{2}$ and $\mathrm{CC}_{13}$, whose window-to-window packing is stable to desolvation, the analogous structure window-to-window for $\mathbf{C C}_{\mathbf{1}}$ is much higher on the crystal energy landscape. We calculate a lattice energy difference of more than $80 \mathrm{~kJ} \mathrm{~mol}^{-1}$ relative to $\mathrm{CC}_{1} \alpha$. This large energy difference would result in a much greater thermodynamic drive for rearrangement to a lower energy structure than for $\mathbf{C C}_{2}$ and $\mathbf{C C}_{13}$, where the vertex methyl substituents stabilise the window-to-window arrangement. The observed instability of the $\mathbf{C C}_{\mathbf{1}}$ window-to-window packing mode to desolvation might therefore be due to inherently unfavorable thermodynamics, as well as more facile structural changes that result from CC's structure and conformational flexibility.

\section{CONCLUSIONS}

Three different organic cage molecules can all be induced to crystallize in the same window-to-window arrangement, analogous to $\mathrm{CC}_{3}$, by the use of a shape-specific 'directomer', 1,4-dioxane. $\mathbf{C C}_{3}$ itself has a strong, native tendency to crystallize in this window-to-window form irrespective of solvent, as confirmed by crystal structure prediction studies. ${ }^{30}$ This is not the case for $\mathbf{C C}_{1}, \mathbf{C C}_{2}$, and $\mathrm{CC}_{13}$ : indeed, so far, these cages only pack in this manner in the presence of the 1,4-dioxane directomer, despite exhaustive screening for $\mathbf{C C}_{\mathbf{1}}$ and $\mathbf{C C}_{2}$ involving 40 different solvents. This window-to-window packing mode is high in energy relative to other unsolvated structures for $\mathbf{C C}_{2}, \mathbf{C C}_{13}$, and, in particular, $\mathbf{C C}_{1}$. Hence, the use of the 1,4-dioxane directomer has allowed us to decouple crystal packing from molecular structure by introducing an auxiliary window-dioxane-window assembly (Fig. 2), which dominates the lattice energy. A conceptual analogy can be drawn with isoreticular $\mathrm{MOFs}^{45}$ and COFs, ${ }^{7,8}$ but here the non-covalent dioxane-cage interaction takes the role of directional intermolecular bonding in enforcing isostructural crystal packing in a series of structurally related materials.
An evolution of physical properties is observed in the structural progression from $\mathbf{C C}_{\mathbf{1}}$ (no methyl groups) to CC2 $_{2}$ (one methyl per vertex) to $\mathbf{C C}_{13}$ (two geminal methyls per vertex). For $\mathbf{C C}_{\mathbf{1}}$ and $\mathbf{C C}_{2}$, there is no significant increase in microporosity with respect to the isostructural $\mathbf{C C}_{3}$ material, but the methyl substituent in $\mathbf{C C}_{2}$ still plays an important role in stabilizing the diamondoid pore structure with respect to solvent removal. For $\mathrm{CC}_{13}$, with its additional methyl substituents, the cages are pushed apart in the crystal structure (Fig. 15), resulting in a double, interpenetrating pore network and a doubling in the degree of microporosity. These 12 disordered methyl groups also solubilize $\mathbf{C C}_{13}$, allowing $20 \% \mathrm{w} / \mathrm{v}$ solutions, which cannot be obtained with $\mathbf{C C}_{1}, \mathbf{C C}_{2}$, or $\mathbf{C C}_{3}$.

The level of crystallinity, and crystal defects, can have a pronounced effect on porosity in these crystalline molecular solids, either in a positive or negative sense depending on the system. This is also the case for extended networks such as MOFs and COFs, and it is wrong to view imperfect crystallinity as a factor that is always detrimental to porosity ${ }^{64,}{ }^{65}$ Here, imperfect crystallinity increases microporosity in the $\mathbf{C C}_{2} \boldsymbol{\beta}$ polymorph; for $\mathbf{C C}_{\mathbf{1 3}} \boldsymbol{\beta}$, the reverse is true.

For applications that rely on molecular selectivity, such as separations, ${ }^{35}$ control over crystalline order might be more important than physical surface area. Quite small differences in crystallization technique can have large effects on porosity, even for batches of material that are chemically identical at the molecular level. Unlike MOFs and COFs, the crystal growth for soluble 'porous molecules' can be completely separated from the chemical synthesis steps. This suggests that researchers in this field, and perhaps reviewers of research articles, should consider the precise details of the final crystallization conditions as of equal importance to the chemical bondforming steps used to prepare the molecules.

\section{ASSOCIATED CONTENT}

Additional experimental, crystallographic and computational details, including video files displaying the rotation of 3dimensional structures to aid visualization. This material is available free of charge via the Internet at http://pubs.acs.org.

\section{AUTHOR INFORMATION}

\section{Corresponding Authors}

t.hasell@liv.ac.uk aicooper@liv.ac.uk

\section{ACKNOWLEDGMENT}

We thank the Engineering and Research Council (EPSRC) for financial support under grant EP/Hooog25/1. A. I. C. is a Royal Society Wolfson Research Merit Award holder. We thank Rob Clowes for assistance with sorption measurements. The authors thank Diamond Light Source for access to beamlines I11 (EE7040) and I19 (MT8728) that contributed to the results presented here. Via our membership of the UK's HPC Materials Chemistry Consortium, which is funded by EPSRC (EP/Fo67496), this work made use of the facilities 
of HECToR, the UK's national high-performance computing service, which is provided by UoE HPCx Ltd at the University of Edinburgh, Cray Inc and NAG Ltd, and funded by the Office of Science and Technology through EPSRC's High End Computing Programme.

\section{REFERENCES}

(1) Handbook of Porous Solids; Schüth, F.; Sing, K. S. W.; Weitkamp, J., Eds.; Wiley VCH: Heidelberg, 2002.

(2) Cundy, C. S.; Cox, P. A. Chem. Rev. 2003, 103, 663.

(3) Bradshaw, D.; Claridge, J. B.; Cussen, E. J.; Prior, T. J.; Rosseinsky, M. J. Acc. Chem. Res. 2005, 38, 273.

(4) Cheetham, A. K.; Férey, G.; Loiseau, T. Angew. Chem. Int. Edit. 1999, 38, 3268.

(5) Kitagawa, S.; Kitaura, R.; Noro, S. Angew. Chem. Int. Edit. 2004, 43, 2334.

(6) Yaghi, O. M.; Li, H. L.; Davis, C.; Richardson, D.; Groy, T. L. Accounts Chem. Res. 1998, 31, 474.

(7) Côté, A. P.; Benin, A. I.; Ockwig, N. W.; O'Keeffe, M.; Matzger, A. J.; Yaghi, O. M. Science 2005, 310, 1166.

(8) Côté, A. P.; El-Kaderi, H. M.; Furukawa, H.; Hunt, J. R.; Yaghi, O. M. J. Am. Chem. Soc. 2007, 129, 12914.

(9) Jiang, J.-X.; Su, F.; Trewin, A.; Wood, C. D.; Campbell, N. L.; Niu, H.; Dickinson, C.; Ganin, A. Y.; Rosseinsky, M. J.; Khimyak, Y. Z.; Cooper, A. I. Angew. Chem. Int. Edit. 2007, 46, 8574 . 5163.

(10) McKeown, N. B.; Budd, P. M. Macromolecules 2010, 43,

(11) Vilela, F.; Zhang, K.; Antonietti, M. Energy $\mathcal{E}$ Environmental Science 2012, 5, 7819. 2367.

(12) Atwood, J. L.; Barbour, L. J.; Jerga, A. Science 2002, 296,

(13) Barbour, L. J. Chem. Commun. 2006, 1163.

(14) Barrer, R. M.; Shanson, V. H. J. Chem. Soc. Chem. Comm. 1976, 333 .

(15) Tian, J.; Thallapally, P. K.; McGrail, B. P. CrystEngComm 2012, 14, 1909.

(16) McKeown, N. B. J. Mater. Chem. 2010, 20, 10588.

(17) Mastalerz, M. Chem.-Eur. J. 2012, 18, 10082.

(18) Mastalerz, M.; Oppel, I. M. Angew. Chem. Int. Edit. 2012, $51,5252$.

(19) Thallapally, P. K.; Dalgarno S. J.; Atwood, J.L.; J. Am. Chem. Soc. 2006, 128, 15060-15061.

(20) Bezzu, C. G.; Helliwell, M.; Warren, J. E.; Allan, D. R.; McKeown, N. B. Science 2010, 327, 1627.

(21) Tranchemontagne, D. J. L.; Ni, Z.; O'Keeffe, M.; Yaghi, O. M. Angew. Chem. Int. Edit. 2008, 47, 5136.

(22) Northrop, B. H.; Zheng, Y.-R.; Chi, K.-W.; Stang, P. J. Acc. Chem. Res. 2009, 42, 1554.

(23) Hutter, J.; Iannuzzi, M.; Schiffmann, F.; VandeVondele, J. WIREs Comput. Mol. Sci. 2013, doi: 10.1002/wcms.1159

(24) Tozawa, T.; Jones, J. T. A.; Swamy, S. I.; Jiang, S.; Adams, D. J.; Shakespeare, S.; Clowes, R.; Bradshaw, D.; Hasell, T.; Chong, S. Y.; Tang, C.; Thompson, S.; Parker, J.; Trewin, A.; Bacsa, J.; Slawin, A. M. Z.; Steiner, A.; Cooper, A. I.Nat. Mater. 2009, 8, 973 .

(25) Jin, Y.; Jin, A.; McCaffrey, R.; Long, H.; Zhang, W. Journal of Organic Chemistry 2012, 77, 7392.

(26) Moure, A.; Luis, S. V.; Alfonso, I. Chem.-Eur. J. 2012, 18,5496 .

(27) Skowronek, P.; Warzajtis, B.; Rychlewska, U.; Gawronski, J. Chem. Commun. 2013, 49, 2524.

(28) Acharyya, K.; Mukherjee, S.; Mukherjee, P. S. J. Am. Chem. Soc. 2013, 135, 554.
(29) Avellaneda, A.; Valente, P.; Burgun, A.; Evans, J. D.; Markwell-Heys, A. W.; Rankine, D.; Nielsen, D. J.; Hill, M. R.; Sumby, C. J.; Doonan, C. J., Angew. Chem. Int. Edit. 2013, 52, 3746.

(30) Schneider, M. W.; Oppel, I. M.; Ott, H.; Lechner, L. G.; Hauswald, H. J. S.; Stoll, R.; Mastalerz, M. Chem.-Eur. J. 2012, 18,836 .

(31) Jones, J. T. A.; Hasell, T.; Wu, X.; Bacsa, J.; Jelfs, K. E.; Schmidtmann, M.; Chong, S. Y.; Adams, D. J.; Trewin, A.; Schiffman, F.; Cora, F.; Slater, B.; Steiner, A.; Day, G. M.; Cooper, A. I. et al., Nature 2011, 474, 367 .

(32) Hasell, T.; Chong, S. Y.; Schmidtmann, M.; Adams, D. J.; Cooper, A. I. Angew. Chem. Int. Edit. 2012, 51, 7154.

(33) Bushell, A. F.; Budd, P. M.; Attfield, M. P.; Jones, J. T. A.; Hasell, T.; Cooper, A. I.; Bernardo, P.; Bazzarelli, F.; Clarizia, G.; Jansen, J. C.Angew. Chem. Int. Edit. 2013, 52, 1253.

(34) Hasell, T.; Zhang, H.; Cooper, A. I. Adv. Mater. 2012, 24, 5732.

(35) Mitra, T.; Jelfs, K. E.; Schmidtmann, M.; Ahmed, A.; Chong, S. Y.; Adams, D. J.; Cooper, A. I. Nat. Chem. 2013, 5, 276.

(36) Brutschy, M.; Schneider, M. W.; Mastalerz, M.; Waldvogel, S. R. Adv. Mater. 2012, 24, 6049.

(37) Brutschy, M.; Schneider, M. W.; Mastalerz, M.; Waldvogel, S. R. Chem. Commun. 2013, 49, 8398.

(38) Hasell, T.; Schmidtmann, M.; Cooper, A. I. J. Am. Chem. Soc. 2011, 133, 14920.

(39) Hasell, T.; Schmidtmann, M.; Stone, C. A.; Smith, M. W.; Cooper, A. I. Chem. Commun. 2012, 48, 4689.

(40) Mitra, T.; Wu, X.; Clowes, R.; Jones, J. T. A.; Jelfs, K. E.; Adams, D. J.; Trewin, A.; Bacsa, J.; Steiner, A.; Cooper, A. I. Chem.-Eur. J. 2011, 17, 10235.

(41) Desiraju, G. R. Angew. Chem. Int. Edit. 1995, 34, 2311.

(42) Jansen, M.; Schön, J. C. Angew. Chem. Int. Edit. 2006, 45, 3406.

(43) Surble, S.; Serre, C.; Mellot-Draznieks, C.; Millange, F.; Ferey, G. Chem. Commun. 2006, 284.

(44) Yuan, D.; Zhao, D.; Sun, D.; Zhou, H.-C. Angew. Chem. Int. Edit. 2010, 49, 5357.

(45) Eddaoudi, M.; Kim, J.; Rosi, N.; Vodak, D.; Wachter, J.; O'Keeffe, M.; Yaghi, O. M. Science 20o2, 295, 469.

(46) Jelfs, K. E.; Wu, X.; Schmidtmann, M.; Jones, J. T. A.; Warren, J. E.; Adams, D. J.; Cooper, A. I. Angew. Chem. Int. Edit 2011, 50, 10653 .

(47) Schneider, M. W.; Hauswald, H. J. S.; Stoll, R.; Mastalerz, M. Chem. Commun. 2012, 48, 9861.

(48) Lydon, D. P.; Campbell, N. L.; Adams, D. J.; Cooper, A. I. Synth. Commun. 2011, 41, 2146.

(49) Perdew, J. P.; Burke, K.; Ernzerhof, M. Phys. Rev. Lett. 1996, 77, 3865 .

(50) Sheldrick, G. M. Acta Crystallog. Section A. 2008, 64, 112.

(51) Dolomanov, O. V.; Bourhis, L. J.; Gildea, R. J.; Howard, J.

A. K.; Puschmann, H. J. Appl. Crystallog. 2009, 42, 339.

(52) Thompson, S. P.; Parker, J. E.; Potter, J.; Hill, T. P.; Birt, A.; Cobb, T. M.; Yuan, F.; Tang, C. C. Rev. Sci. Instr. 2oog, 8o, 075107, doi: 10.1063/1.3167217

(53) Coelho, A. A. TOPAS-Academic version 4.1. 2007. http://www.topas-academic.net.

(54) Willems, T. F.; Rycroft, C.; Kazi, M.; Meza, J. C.; Haranczyk, M. Microporous Mesoporous Mat. 2012, 149, 134.

(55) Robeson, L. M. J. Membrane Sci. 1991, 62, 165.

(56) VandeVondele, J.; Hutter, J. J.Chem. Phys. 2007, 127, 114105.

(57) Goedecker, S.; Teter, M.; Hutter, J. Phys. Rev. B 1996, $54,1703$.

(58) Grimme, S.; Antony, J.; Ehrlich, S.; Krieg, H. J. Chem. Phys. 2010, 132, 154104 . 
(59) Smith, W.; Yong, C. W.; Rodger, P. M. Mol. Simulat. 2002, 28,385 .

(6o) Holden, D.; Jelfs, K. E.; Cooper, A. I.; Trewin, A.; Willock, D. J. J.Phys. Chem. C 2012, 116, 16639.

(61) Jones, J. T. A.; Holden, D.; Mitra, T.; Hasell, T.; Adams, D. J.; Jelfs, K. E.; Trewin, A.; Willock, D. J.; Day, G. M.; Bacsa, J.; Steiner, A.; Cooper, A. I. Angew. Chem. Int. Edit. 2011, 50, 749.

(62) Hasell, T.; Wu, X. F.; Jones, J. T. A.; Bacsa, J.; Steiner, A.; Mitra, T.; Trewin, A.; Adams, D. J.; Cooper, A. I. Nat. Chem. 2010, 2, 750 .

(63) Hasell, T.; Chong, S. Y.; Jelfs, K. E.; Adams, D. J.; Cooper, A. I. J. Am. Chem. Soc. 2012, 134, 588.

(64) Jiang, S.; Jelf, K. E.; Holden, D.; Hasell, T.; Chong , S. Y.; Haranczyk, M.; Trewin, A.; Cooper, A. I. J. Am. Chem. Soc. DOI: 10.1021/ja407374k;

(65) Jiang, S.; Jones, J. T. A.; Hasell, T.; Blythe, C. E.; Adams, D. J.; Trewin, A.; Cooper, A. I. Nat. Commun. 2011, 2, 207.

Authors are required to submit a graphic entry for the Table of Contents (TOC) that, in conjunction with the manuscript title, should give the reader a representative idea of one of the following: A key structure, reaction, equation, concept, or theorem, etc., that is discussed in the manuscript. Consult the journal's Instructions for Authors for TOC graphic specifications.
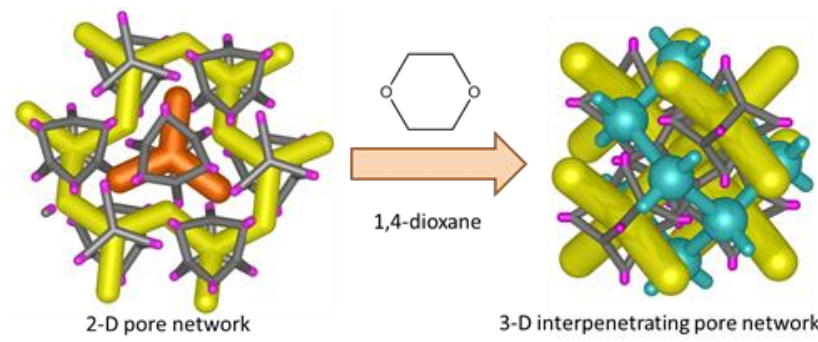

3-D interpenetrating pore network 